\title{
Separation of $\mathrm{Cr}$ (III) from by Functionalized Graphene Oxide with Covalently Linked Porphyrin (GO- $\left.\mathrm{H}_{2} \mathrm{NP}\right)$ Adsorbed on Surfactant Coated $\mathrm{C}_{18}$
}

\author{
KAMELIA KARIMNEZHAD ${ }^{1}$ and ALI MOGHIMI ${ }^{2 *}$ \\ ${ }^{1}$ Faculty of science, UniversitiTeknologi Malaysia, Skudai, Johor, 81310, Malaysia \\ ${ }^{2}$ Department of Chemistry, Varamin (Pishva) Branch, Islamic Azad University, Varamin Iran \\ *Corresponding author E-mail:alimoghimi@iauvaramin.ac.ir; kamran9537@yahoo.com
}

http://dx.doi.org/10.13005/ojc/300122

(Received: November 25, 2013; Accepted: January 07, 2014)

\begin{abstract}
A novel, simple, sensitive and effective method has been developed for preconcentration of $\mathrm{Cr}$ (III) on functionalized Graphene oxide with covalently linked porphyrin $\left(\mathrm{GO}-\mathrm{H}_{2} \mathrm{NP}\right)$ solid-phase extraction adsorbent. The stability of a chemical $\left(\mathrm{GO}-\mathrm{H}_{2} \mathrm{NP}\right)$, especially in concentrated hydrochloric acid, was then used as a recycling and pre-concentration reagent. The method is based on selective chelation of $\mathrm{Cr}(\mathrm{III})$ on surfactant coated $\mathrm{C}_{18}$, modified with functionalized $\mathrm{GO}$ with covalently linked porphyrin (GO- $\left.\mathrm{H}_{2} \mathrm{NP}\right)$. The retained ions were then eluted with $4 \mathrm{ml}$ of $3 \mathrm{M}$ nitric acid and determined by flame atomic absorption spectrometry (FAAS) at $283.3 \mathrm{~nm}$ for $\mathrm{Cr}$. The influence of flow rates of sample and eluent solutions, $\mathrm{pH}$, breakthrough volume, effect of foreign ions on chelation and recovery were investigated. $1.5 \mathrm{~g}$ of surfactant coated $\mathrm{C}_{18}$ adsorbs $40 \mathrm{mg}$ of the functionalized Graphene oxide with covalently linked porphyrin $\left(\mathrm{GO}-\mathrm{H}_{2} \mathrm{NP}\right)$ base which in turn can retain $20.0 \pm 0.9 \mathrm{mg}$ of each of

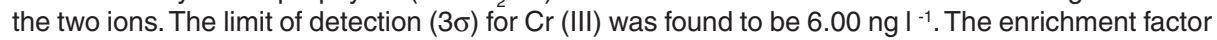
for both ions is 100 . The mentioned method was successfully applied on the determination of $\mathrm{Cr}$ in different water samples. The ions were also speciated by means of a three columns system.
\end{abstract}

Key words: Determination of $\mathrm{Cr}(\mathrm{III})$, Pre-concentration, functionalized Graphene oxide, covalently linked porphyrin $\left(\mathrm{GO}-\mathrm{H}_{2} \mathrm{NP}\right)$, FAAS.

\section{INTRODUCTION}

Toxicological studies have proved that the degree of toxicity of an element directly depends on the species in which it is present. $\mathrm{Cr}$ (III) is considered as an essential micronutrient for humans and mammals in order to maintain glucose metabolism, where as $\mathrm{Cr}(\mathrm{VI})$ is a potentially carcinogenic agent. ${ }^{1}$ The significant drawbacks of $\mathrm{Cr}(\mathrm{VI})$ are breathing disturbances, liver and digestion malfunctions, dermal corrosion and skin allergies. ${ }^{2}$ Therefore, It is necessary to control the level of chromium in industrial effluent, natural and drinking waters. Speciation of chromium in environmental samples is of prime importance. 
Therefore there are numerous methods and techniques concerning chromium speciation and determination including liquid-liquid extraction after complex formation ${ }^{3-4}$, solid-liquid extraction ${ }^{5-9}$, LC-AAS $^{10-11}$,FIA-AAS ${ }^{38,39}$, spectrophotometric ${ }^{12,39}$, ICP-AES ${ }^{13}$, and $\mathrm{NAA}^{14}$. However, some of these techniques are currently, time consuming and have elaborate sample preparation steps and low enrichment factors.

Solid phase extraction (SPE) methods are the best alternatives for traditional classic methods due to selective removal of trace amounts of metal ions from their matrices. SPE determinations can be carried out on different efficient ways. One of the most appropriative performation features of SPE is achieved by using octadecyl silica membrane disks. SPE reduce the use of toxic solvent, disposal costs, and extraction time ${ }^{15-16}$. The octadecyl silica membrane disks involves shorter sample processing time and decreased plugging due to the large crosssectional area of the disk and small pressure drop which allows higher flow-rates; reduced channeling resulting from the use of sorbent with smaller particle size and a greater mechanical stability of the sorbent bed $^{17}$.

In our previous attempts, we modified SPE membrane disks with suitable compounds for selective determination of chromium ${ }^{18-19,36}$ and lead ${ }^{21}$. Meanwhile, other investigators have successfully utilized these sorbents for quantitative extraction and monitoring trace amounts of lead ${ }^{22-24}$, copper ${ }^{25-26}$, silver $^{28-29}$, mercury ${ }^{30-31}$, cadmium $^{32}$, palladium ${ }^{33}, \mathrm{Ce}^{34}$ and $\mathrm{UO}_{2}{ }^{35}$.

The main goal of the present work is the development of a fast, sensitive and efficient way for enrichment and extraction of trace amounts of $\mathrm{Cr}$ (III) from aqueous media by means of a surfactant coated $\mathrm{C} 18$ modified with $\mathrm{GO}$ with covalently linked porphyrin(I, shown in Fig. 1).

Such a determination has not been reported in the literature. The structure of functionalized Graphene oxide with covalently linked porphyrin $\left(\mathrm{GO}-\mathrm{H}_{2} \mathrm{NP}\right)$ is shown in Fig. 1. The chelated ions were desorbed and determined by FAAS. The modified solid phase could be used at least 50 times with acceptable reproducibility without any change in the composition of the sorbent, GO- $\mathrm{H}_{2} \mathrm{NPor}$ SDS. This work investigated the applications of nanoGraphene oxide with covalently linked porphyrin (GO- $\mathrm{H}_{2} \mathrm{NP}$ ) like the $\mathrm{C}_{18} \mathrm{SPE}$ mini-column for selective extraction and solid phase pre-concentration of $\mathrm{Cr}$ (III) from aqueous and natural water samples.

\section{EXPERIMENTAL}

\section{Reagents and Apparatus}

All solutions were prepared with doubly distilled deionized water. $\mathrm{C}_{18}$ powder for chromatography with a diameter of about $50 \mu \mathrm{m}$ was obtained from Katayama Chemicals. It was conditioned before use by being suspended in $3 \mathrm{M}$ nitric acid for $20 \mathrm{~min}$, and then washed two times with water. Sodium dodecyl solfate (SDS) was obtained from Merck and used without any further purification. 1-(3-Dimethylaminopropyl)-3-ethylcarbodiimide hydrochloride (EDC) and N-hydroxysuccinimide (NHS) were purchased from Aldrich. Graphene oxide (Guangfu Fine Chemical Research Institute, Tianjin, China) was used to prepare GO- $\mathrm{H}_{2} \mathrm{NP}$.

\section{Preparation of GO}

Graphite $(5 \mathrm{~g})$ was added to a vigorously stirring, ice-cooled mixture of sulfuric acid $(88 \mathrm{~mL})$ and nitric acid ( $44 \mathrm{~mL}$ ). After the graphite was well dispersed, potassium chlorate $(55 \mathrm{~g})$ was added slowly, in portions, over $15 \mathrm{~min}$, with simultaneous purging with nitrogen gas, to avoid a rapid increase of the temperature and to reduce the concentration of the generated chlorine dioxide gas. Then, the reaction mixture was allowed to stir for $96 \mathrm{~h}$ at room temperature. On completion of the reaction, the mixture was poured into $4 \mathrm{~L}$ of ice water and filtered through a $0.45 \mathrm{~mm}$ PTFE membrane filter. The graphite oxide was redispersed and washed with 5 $\mathrm{L}$ of a $5 \% \mathrm{HCl}$ solution and then washed repeatedly with deionized water until the $\mathrm{pH}$ of the filtrate was neutral. The filter cake was then redispersed in methanol and after filtration was dried in a vacuum oven at $60^{\circ} \mathrm{C}$ overnight and then under atmospheric pressure at $120^{\circ} \mathrm{C}$ for $8 \mathrm{~h}$ to give $\mathrm{GO}$ as a browngray powder $(3.9 \mathrm{~g})$.

\section{Synthesis of GO- $\mathrm{H}_{2} \mathrm{NP}$}

GO[36] (15 mg) was stirred in $20 \mathrm{~mL}$ of oxalyl chloride at $80{ }^{\circ} \mathrm{C}$ for $24 \mathrm{~h}$ to activate the carboxylic units by forming the corresponding 
acyl chlorides. Then, the reaction mixture was evaporated to remove the excess oxalyl chloride and the brownish remaining solid (GO-COCl) was washed with anhydrous tetrahydrofuran (THF). After centrifugation, the resulting solid material was dried at room temperature under vacuum. For the covalent coupling between the free amino function of $\mathrm{H}_{2} \mathrm{NP}$ and the acyl chloride of GO, $15 \mathrm{mg}$ of GO-COCl was treated under anaerobic, dry conditions with $7 \mathrm{mg}$ of porphyrin dissolved in $6 \mathrm{ml}$ of dry THF at room temperature for $72 \mathrm{~h}$. The hybrid material, namely GO- $\mathrm{H}_{2} \mathrm{NP}$, was obtained as a brown-gray solidby filtration of the reaction mixture through $0.2 \mathrm{~mm}$
PTFE filter and the filtrate was sufficiently washed with methylene chloride $(4 \times 20 \mathrm{ml})$ to remove nonreacted free $\mathrm{H}_{2} \mathrm{NP}$ and then with diethyl ether $(2 \times$ $20 \mathrm{~mL}$ ) before being dried under vacuum ${ }^{20}$.

\section{Column preparation}

GO- $\mathrm{H}_{2} \mathrm{NP}(40 \mathrm{mg})$ was packed into an SPE mini-column (6.0 cm $\times 9 \mathrm{~mm}$ i.d., polypropylene). A polypropylene frit was placed at each end of the column to prevent loss of the adsorbent. Before use, $0.5 \mathrm{~mol} \mathrm{~L}^{-1} \mathrm{HNO}_{3}$ and DDW were passed through the column to clean it.

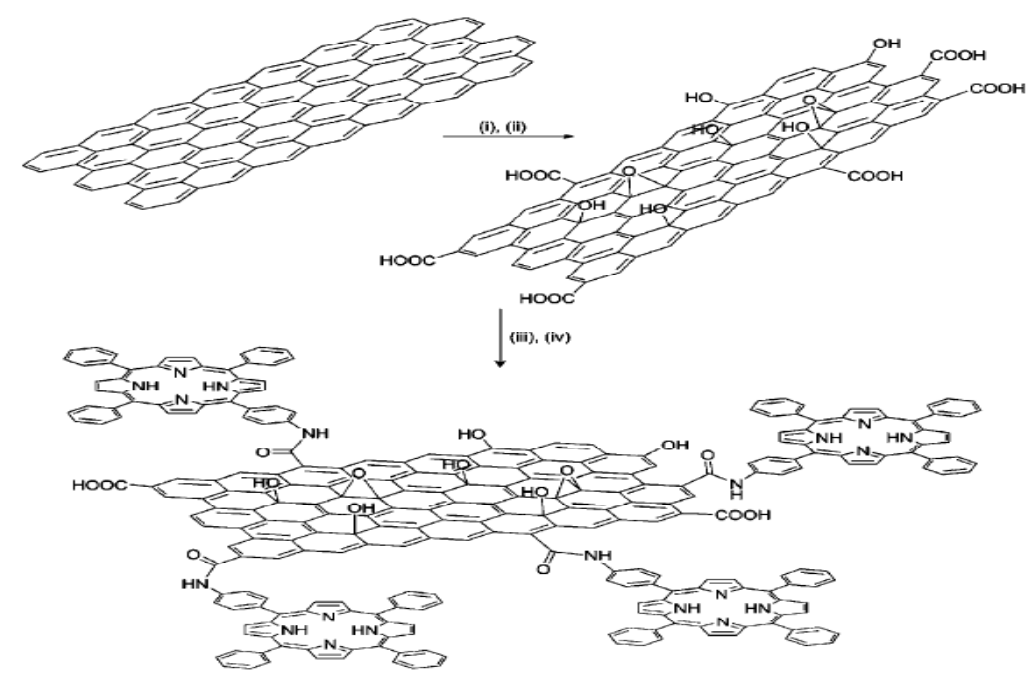

Schematic 1.A schematic illustration for the preparation of GO with covalently linked $\mathrm{H}_{2}$ NP. (i) $\mathrm{H}_{2} \mathrm{SO}_{4} / \mathrm{HNO}_{3}(2: 1 \mathrm{v} / \mathrm{v})$, (ii) $\mathrm{KClO}_{3}, 96 \mathrm{~h}$, (iii) $(\mathrm{COCl})_{2}, 80{ }^{\circ} \mathrm{C}, 24 \mathrm{~h}$, (iv) 5-(4-aminophenyl)-10,15,20triphenyl-21,23H-porphyrin, THF, r.t., $72 \mathrm{~h}$.

\section{Apparatus}

The $\mathrm{pH}$ measurements were conducted with an ATC pH meter (EDT instruments, GP 353) calibrated against two standard buffer solutions of $\mathrm{pH} 4.0$ and 9.2. Infrared spectra of $\mathrm{GO}-\mathrm{H}_{2} \mathrm{NP}$ were carried out from the $\mathrm{KBr}$ pellet by a PerkinElmer 1430 ratio recording spectrophotometer. Atomic absorption analysis of all the metal ions except $\mathrm{Zn}(\mathrm{II})$ was performed with a Perkin-Elmer 2380 flame atomic absorption spectrometer. $\mathrm{Zn}$ (II) determinations were performed by a Varian Spect AA-10. Raman spectrophotometer analysis was performed with a Perkin-Elmer.

\section{Preparation of admicell column}

Solution was added to $40 \mathrm{ml}$ of water containing $1.5 \mathrm{~g}$ of $\mathrm{C}_{18}$, and $150 \mathrm{mg}$ of the above Graphene oxide with covalently linked porphyrinwas loaded after washing acetone, $1 \mathrm{moll}^{-1} \mathrm{HNO}_{3}$ solution and water, respectively. The $\mathrm{pH}$ of the suspension was adjusted to 2.0 with the addition of $3 \mathrm{~mol} \mathrm{~L}^{-1}$ $\mathrm{HNO}_{3}$ and stirred by a mechanical stirrer for $20 \mathrm{~min}$. Then the top liquid was decanted (and discarded) and the remaining $\mathrm{C}_{18}$ was washed three times with water, then with $5 \mathrm{ml}$ of $3 \mathrm{~mol} \mathrm{~L}-1 \quad \mathrm{HNO}_{3}$ and again three times with water. The prepared sorbent was transferred to a polypropylene tube (i.d $5 \mathrm{~mm}$, length $10 \mathrm{~mm})$. 
Determination of $\mathrm{Cr}^{2+}$ contents in working samples were carried out by a Varian spectra A.200 model atomic absorption spectrometerequipped with a high intensity hallow cathode lamp(HI$\mathrm{HCl}$ ) according to the recommendations of the manufacturers. These characteristics are tabulated in (Table 1). A metrohm $691 \mathrm{pH}$ meter equipped with a combined glass calomel electrode was used for $\mathrm{pH}$ measurements.

\section{Procedure}

The $\mathrm{pH}$ of a solution containing $100 \mathrm{ng}$ of each $\mathrm{Cr}$ (III) was adjusted to 2.0. This solution was passed through the admicell column with a flow rate of $5 \mathrm{ml} \mathrm{min}^{-1}$. The column was washed with $10 \mathrm{ml}$ of water and the retained ions were desorbed with 1 $\mathrm{ml}$ of $3 \mathrm{M} \mathrm{HNO}_{3}$ with a flow rate of $2 \mathrm{ml} \mathrm{min}^{-1}$. The desorption procedure was repeated 3 more times. All the acid solutions ( $4 \mathrm{ml}$ all together) were collected in a $10 \mathrm{ml}$ volumetric flask and diluted to the mark with water. The concentrations of $\mathrm{Cr}$ in the solution were determined by FAAS at 283.3.

\section{Determination of $\mathbf{C r}$ in water samples}

Polyethylene bottles were soaked in $1 \mathrm{~mol}$ $\mathrm{L}^{-1} \mathrm{HNO}_{3}$ overnight, and washed two times with water and used for sampling. The water sample was filtered through a $0.45 \mu \mathrm{m}$ porous filter. The $\mathrm{pH}$ of a 1000 $\mathrm{ml}$ portion of each sample was adjusted to 2.0(3 M $\mathrm{HNO}_{3}$ ) and passed through the column under a flow rate of $5 \mathrm{ml} \mathrm{min}^{-1}$. The column was washed with water and the ions were desorbed and determined as the above mentioned procedure.

\section{Speciation of $\mathrm{Cr}$ in water samples}

This procedure is reported in several articles. The method has been evaluated and optimized for speciation and its application on complex mixtures ${ }^{18}$. The chelating cation exchanger (Chelex-100) and anion exchanger, (Dowex 1X-8) resins were washed with $1 \mathrm{M} \mathrm{HCl}$, water, $1 \mathrm{M} \mathrm{NaOH}$ and water, respectively. $1.2 \mathrm{~g}$ of each resin was transferred to separate polyethylene columns. Each column was washed with $10 \mathrm{ml}$ of $2 \mathrm{M} \mathrm{HNO}_{3}$ and then $30 \mathrm{ml}$ of water. The $\mathrm{C}_{18}$ bounded silica adsorber was conditioned with $5 \mathrm{ml}$ of methanol in a separate column, then with $5 \mathrm{ml}$ of $2 \mathrm{M} \mathrm{HNO}_{3}$ and at the end with $20 \mathrm{ml}$ of water. $5 \mathrm{ml}$ of methanol was added on top of the adsorber, and passed through it until the level of methanol reached just the surface of the adsorber. Then water was added to it and connected to the other two columns. A certain volume of water sample was filtered through a $0.45 \mu \mathrm{m}$ filter and then passed through the three column system, Dowex 1X-8, RP-C18 silica adsorber and Chelex-100, respectively. The columns were then separated. The anion and cation exchanger columns were washed with $10 \mathrm{ml}$ of $2 \mathrm{M} \mathrm{HNO}_{3}$ and the $\mathrm{C}_{18}$ column with 10 $\mathrm{ml}$ of $1 \mathrm{M} \mathrm{HCl}$. The flow rate of eluents was $1 \mathrm{ml}$ $\mathrm{min}^{-1}$. The $\mathrm{Cr}$ content of each eluted solution was determined by FAAS.

\section{RESULTS AND DISCUSSION}

The treatment of Graphene oxide with covalently linked porphyrin ( $\left.\mathrm{GO}-\mathrm{H}_{2} \mathrm{NP}\right)$ can lead to the derivatization of both the edge carboxyl and surface hydroxyl functional groups via formation of amides [20] or carbamateesters[21], respectively.

The formation of GO- $\mathrm{H}_{2} \mathrm{NP}$ was followed by ATRIR spectroscopy.Initially, in the spectrum of GO, the carbonyl vibration appears at $1716 \mathrm{~cm}^{-1}$, while there are fingerprints at $3616 \mathrm{~cm}^{-1}$ and $3490 \mathrm{~cm}^{-1}$ due to the presence of hydroxyl species at the basal plane of graphene. The covalent linkage of $\mathrm{H}_{2} \mathrm{NP}$ with the acyl chloride activated $\mathrm{GO}$ is evident from the presence of a band at $1630 \mathrm{~cm}^{-1}$, which is characteristic for the carbonyl groups of the amide units ${ }^{24}$.

The amount of porphyrin attached onto the graphene sheet was evaluated by thermogravimetric analysis. As compared with the TGA results of pure graphite, which is thermally stable up to $900{ }^{\circ} \mathrm{C}$ under nitrogen, and GO which decomposes above $600^{\circ} \mathrm{C}$, after having lost the oxygenated species at $240{ }^{\circ} \mathrm{C}$ (i.e. $14.7 \%$ weight loss), the $6 \%$ weight loss occurred in the temperature range $250-550^{\circ} \mathrm{C}$ for the $\mathrm{GO}-\mathrm{H}_{2} \mathrm{NP}$ material, is attributed to the decomposition of $\mathrm{H}_{2} \mathrm{NP}$ (Fig. 2).

The GO- $\mathrm{H}_{2} \mathrm{NP}$ material forms a stable dispersion in DMF at a concentration not exceeding $1 \mathrm{mg} \mathrm{mL}^{-1}$. The electronic absorption spectrum of GO- $\mathrm{H}_{2} \mathrm{NP}$ in DMF (Fig. 3), shows ( $\mathrm{i}$ )a broad signal monotonically decreasing from the UV to the visible region, which is attributed to $\mathrm{GO}$ and (ii) a characteristic band at $420 \mathrm{~nm}$ (Soret-band) corresponding to the covalently grafted $\mathrm{H}_{2} \mathrm{NP}$ units (the Q-bands at 516, 557, 589 and $648 \mathrm{~nm}$ were flattened to the base line in the $\mathrm{GO}-\mathrm{H}_{2} \mathrm{NP}$ material). 


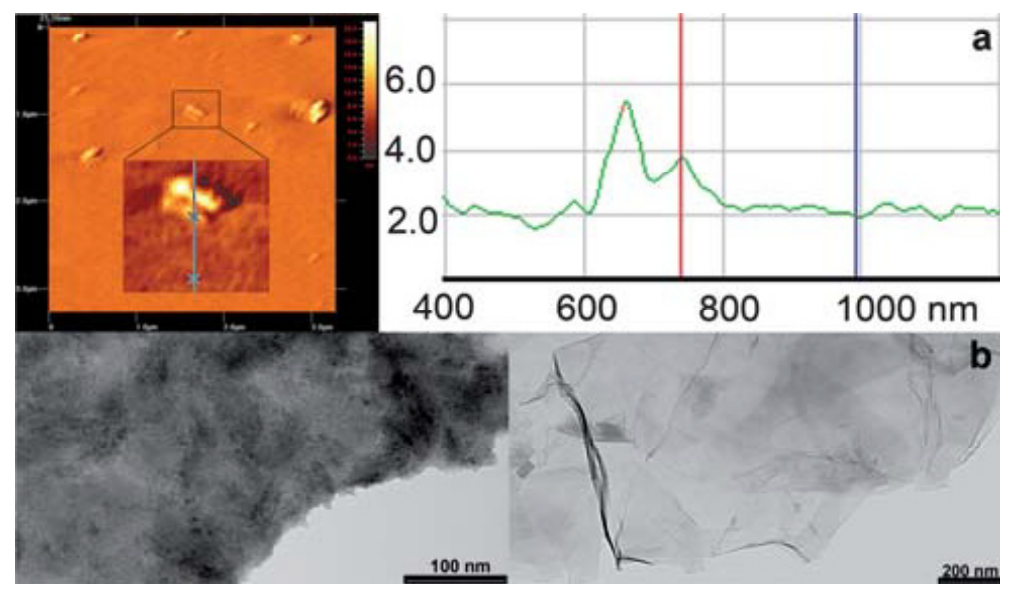

Fig. 1 (a): Representative AFM image of GO- $\mathrm{H}_{2}$ NP and profile analysis showing a height of $1.77 \mathrm{~nm}$ for the enlarged region. Section analysis of other regions of the image show height ranges of 1.5 $3.5 \mathrm{~nm}$. (b) TEM images of the intact graphite (left panel) and GO- $\mathrm{H}_{2} \mathrm{NP}$ hybrid material (right

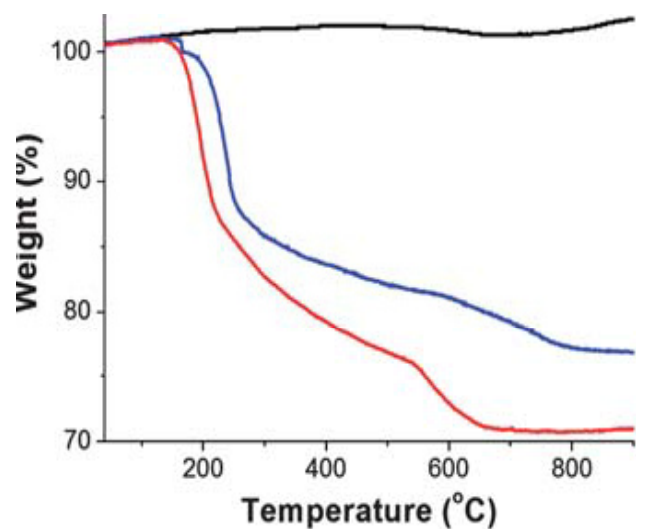

Fig. 2: The TGA graphs of graphite (black), GO (blue) and GO- $\mathrm{H}_{2}$ NP (red), obtained under an inert atmosphere

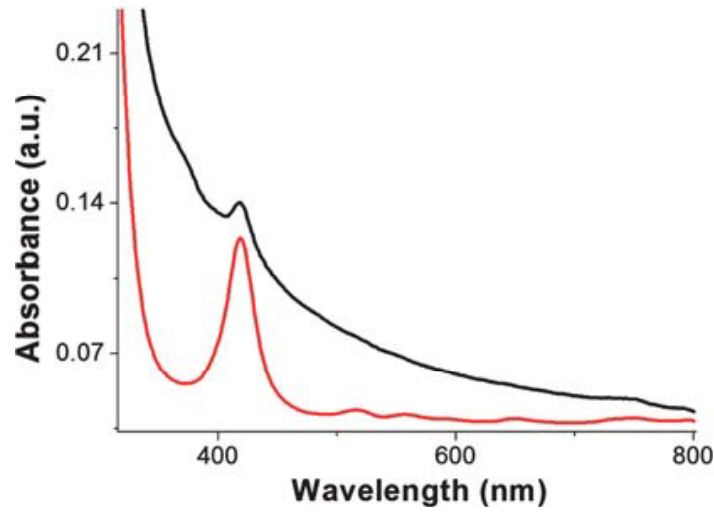

Fig. 3: The UV-vis spectra of GO- $\mathrm{H}_{2} \mathrm{NP}$ (black) and free $\mathrm{H}_{2} \mathrm{NP}$ (red), obtained in DMF

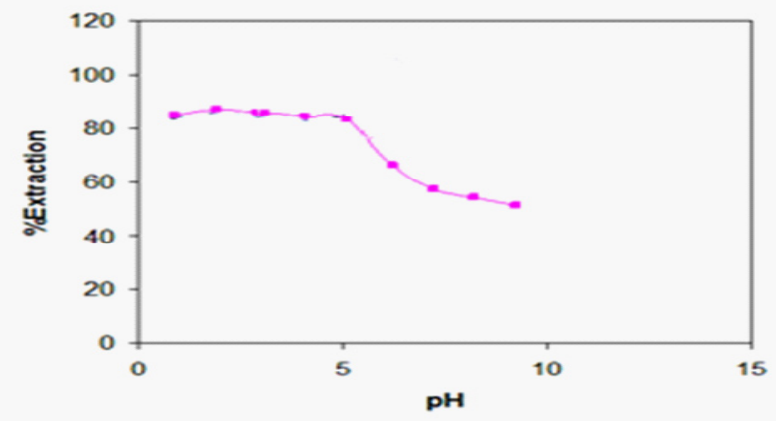

Fig. 4: Extraction percentage of $\mathrm{Cr}(\mathrm{III})$ against pH 
Interestingly, the absorption of porphyrin in the GO- $\mathrm{H}_{2} \mathrm{NP}$ material is broadened, shortened and bathochromically shifted (ca. $2 \mathrm{~nm}$ ) as compared to that of the free $\mathrm{H}_{2} \mathrm{NP}$, a result that corroborates not only the linkage of porphyrin with the GO sheets but also electronic interactions between the two species (i.e. $\mathrm{GO}$ and $\mathrm{H}_{2} \mathrm{NP}$ ) in the ground state. These results are in agreement with studies based on other hybrid systems consisting of porphyrins covalently grafted to carbon nanotubes and nanohorns ${ }^{21}$.

\section{Stability studies}

The stability of the newly synthesized GO- $\mathrm{H}_{2}$ NP phases was performed in different buffer solutions $(\mathrm{pH} 1,2,3,4,5,6$ and $0.1 \mathrm{M}$ sodium acetate) in order to assess the possible leaching or hydrolysis processes. Because the metal capacity values determined in Section 3.2 revealed that the highest one corresponds to $\mathrm{Cr}$ (III), this ion was used to evaluate the stability measurements for the GO$\mathrm{H}_{2} \mathrm{NP}$ phase ${ }^{18}$. The results of this study proved that the GO- $\mathrm{H}_{2} \mathrm{NP}$ is more resistant than the chemically adsorbed analog, especially in 1.0, 5.0 and $10.0 \mathrm{M}$ hydrochloric acid with a hydrolysis percentage of $2.20,6.10$ and 10.50 for each phase, respectively.

Thus, these stability studies indicated the suitability of each phase for application in various acid solutions especially concentrated hydrochloric acid and extension of the experimental range to very strong acidic media which is not suitable for other normal and selective chelating ion exchangers based on a nano polymeric matrix ${ }^{17}$. Finally, the $\mathrm{GO}-\mathrm{H}_{2} \mathrm{NP}$ phases were also found to be stable over a range of 1 year during the course of this work.

$\mathrm{GO}-\mathrm{H}_{2} \mathrm{NP}$ is insoluble in water. Primary investigations revealed that surfactant coated $\mathrm{C}_{18}$ could not retain $\mathrm{Cr}(\mathrm{III})$ cations, but when modified with the GO- $\mathrm{H}_{2} \mathrm{NP}$, it retains these cations selectively. It was then decided to investigate the capability of the $\mathrm{GO}-\mathrm{H}_{2} \mathrm{NP}$ as a ligand for simultaneous preconcentration and determination of $\mathrm{Cr}$ on admicell. The $\mathrm{C}_{18}$ surface in acidic media $(1<\mathrm{pH}<6)$ attracts protons and becomes positively charged. The hydrophilic part of SDS $\left(-\mathrm{SO}_{3}^{-}\right)$, is attached strongly to these protons. On the other hand, the $\mathrm{GO}-\mathrm{H}_{2} \mathrm{NP}$ is attached to the hydrophobe part of SDS and retain small quantities of metallic actions ${ }^{17}$.

\section{Effect of pH}

The effect of $\mathrm{pH}$ of the aqueous solution on the extraction of $100 \mathrm{ng}$ of each of the cations $\mathrm{Cr}$ (III) was studied in the $\mathrm{pH}$ range of 1-10. The $\mathrm{pH}$ of the solution was adjusted by means of either $0.01 \mathrm{~mol} \mathrm{~L}^{-1}$ $\mathrm{HNO}_{3}$ or $0.01 \mathrm{~mol} \mathrm{~L}^{-1} \mathrm{NaOH}$. The results indicate that complete chelation and recovery of $\mathrm{Cr}$ (III) occurs in a pH range of 2-4 shown in Fig. 2. It is probable that at higher $\mathrm{pH}$ values, the cations might be hydrolyzed and complete desorption does not occur. Hence, in order to prevent hydrolysis of the cations and also keeping SDS on the $\mathrm{C}_{18}, \mathrm{pH}=2.0$ was chosen for further studies.

\section{Effect of flow rates of solutions}

The effect of the solution's flow rate of the cations on their chelation on the substrate was also studied. It was indicated that flow rates of 1-5 $\mathrm{ml} \mathrm{min} \mathrm{m}^{-1}$ would not affect the retention efficiency of the substrate. Higher flow rates cause incomplete chelation of the cations on the sorbent. The similar range of flow rate for chelation of cations on modified $\mathrm{C}_{18}$ with SDS and a GO- $\mathrm{H}_{2} \mathrm{NP}$ has been reported in the literature ${ }^{17}$. A flow rate of $1-2 \mathrm{ml} \mathrm{min}^{-1}$ for desorption of the cations with $4 \mathrm{ml}$ of $4 \mathrm{M} \mathrm{HNO}_{3}$ has been found suitable. Higher flow rates need a larger volume of acid. Hence, flow rates of $5 \mathrm{ml} \mathrm{min}^{-1}$ and $2 \mathrm{ml} \mathrm{min}{ }^{-1}$ were used for sample solution and eluting solvents throughout, respectively.

\section{Effect of the GO- $\mathrm{H}_{2} \mathrm{NP}$ quantity}

To study an optimum quantity of the GO$\mathrm{H}_{2} \mathrm{NP}$ on quantitative extraction of $\mathrm{Cr}, 50 \mathrm{ml}$ portions of solutions containing $100 \mathrm{ng}$ of each cation were passed through different columns, the sorbent of which were modified with various amounts, between $10-50 \mathrm{mg}$ of the GO- $\mathrm{H}_{2} \mathrm{NP}$. The best result was obtained on the sorbent which was modified with $40 \mathrm{mg}$ of the $\mathrm{GO}-\mathrm{H}_{2} \mathrm{NP}$.

\section{Figures of merit}

The breakthrough volume is of prime importance for solid phase extractions. Hence, the effect of sample volume on the recovery of the cations was studied. $100 \mathrm{ng}$ of each cation was dissolved in $50,100,500$ and $1000 \mathrm{ml}$ of water. It was indicated that in all the cases, chelation and desorption of the cations were quantitative. It was then concluded that the breakthrough volume could be even more than $1000 \mathrm{ml}$. Because the sample volume was $1000 \mathrm{ml}$ 
and the cations were eluted into $10 \mathrm{ml}$ solution, the enrichment factor for both cations is 100 , which is easily achievable. The maximum capacity of $1.5 \mathrm{~g}$ of the substrate was determined as follows; $500 \mathrm{ml}$ of a solution containing $50 \mathrm{mg}$ of each cation was passed through the column. The chelated ions were eluted and determined by FAAS. The maximum capacity of the sorbent for three individual replicates was found to be $20.0 \pm 0.9 \mu \mathrm{g}$ of each cation. The limit of detection (3ó) for the cations ${ }^{17}$ was found to be 5.40 $\mathrm{ngL}^{-1}$ for $\mathrm{Cr}$ ions. Reproducibility of the method for extraction and determination of $100 \mathrm{ng}$ of each cation in a $50 \mathrm{ml}$ solution was examined. As the results of seven individual replicate measurements indicated, they were $2.85 \%$ and $2.98 \%$ for $\mathrm{Cr}(\mathrm{III})$.

\section{Effect of foreign ions}

The effect of foreign ions was also investigated on the measurements of Cr. Here a certain amount of foreign ion was added to $50 \mathrm{ml}$ of the sample solution containing $100 \mathrm{ng}$ of each $\mathrm{Cr}$ (III) with a $\mathrm{pH}$ of 2.5. The amounts of the foreign ions and the percentages of the recovery of $\mathrm{Cr}$ are listed in Table 2. As it is observed, it is possible to determine $\mathrm{Cr}$ without being affected by the mentioned ions.

\section{Analysis of the water samples}

The prepared sorbent was used for analysis of real samples. To do this, the amounts of $\mathrm{Cr}$ were determined in different water samples namely: distilled water, tap water of Tehran ( taken after 10 min operation of the tap), rain water (Tehran, 20 January, 2013), snow water (Tehran, 7 February, 2013), and two synthetic samples containing different cations. The results are tabulated in Table 3 . As it is seen, the amounts of $\mathrm{Cr}$ added to the water samples are extracted and determined quantitatively which indicates accuracy and precision of the present method.

Separation and speciation of cationswere completed by three columns system. It is possible to pre-concentrate and at the same time separate the neutral metal complexes of $\mathrm{GO}-\mathrm{H}_{2} \mathrm{NP}$, anionic complexes and free ions from each other by this method $^{17}$. Water samples were passed through the three connected columns: anion exchanger, $\mathrm{C}_{18}$-silica adsorber and chelating cation exchanger. Each species of $\mathrm{Cr}$ is retained in one of the columns; anionic complexes in the first column, neutral complexes of GO- $\mathrm{H}_{2} \mathrm{NP}$ in the second, and free ions in the third. The results of passing certain volumes of different water samples through the columns are listed in Table 4. According to the results, it is indicated that $\mathrm{Cr}$ is present only as cations. On the other hand, the t-test comparing the obtained mean values of the present work with those published indicate no significant difference between them. We have proposed a method for the determination and preconcentration of $\mathrm{Cr}$ in water samples using surfactant coated $\mathrm{C}_{18}$ impregnated with a $\mathrm{GO}$ with covalently linked porphyrinbase. The proposed method offers a simple, highly sensitive, accurate and selective method for the determination of trace amounts of $\mathrm{Cr}(\mathrm{III})$ in water samples. The method developed was simple, reliable, and precise for determining $\mathrm{Cr}$ in water. Also, the proposed method was free of interference compared to conventional procedures to determine $\mathrm{Cr}^{17,21,38-39}$. The methode can be successfully applied to the separation and determination of $\mathrm{Cr}$ in binary mixtures.

\section{ACKNOWLEDGMENTS}

The authors wish to thank the Chemistry Department of Islamic Azad University, Varamin Branch, for their financial support.

\section{REFERENCES}

1. Nriagu, J. O.; Nicboer, E. Chromium in the Natural and Human Environment, New York (1988).

2. Camel, V. Spectrochim. ActaPart B, 58: 1177 (2003).

3. Gonzalez, E. B.; Garcia, J. B.; Barrera, P .B.; Barrera, A.B. Fresenius J .Anal.Chem., 344: 301 (1992).

4. Subramanian, K.S. Anal.chem , 60: 11
(1988).

5. Romero, R. M. C.; Biurrun, M. C.Y; Barrera, M. P. B. Anal.Chim.Acta, 327: 37 (1996).

6. Pannain, M. C.; Santelli, R. E. Talanta, 42: 1609 (1995).

7. A.I.El-Shewany, A.H. Atta, F.A. Kora and K.M. Elsabawy, Orient J. Chem., 29(1): 01-08 (2013).

8. B.Pasullean, C.M.Davidson, D.Little john , 
J.Anal.Atom.Spectrom. 10: 241 (1995).

9. Jimenez, M. S.; Martin, I.; Mir, J. M.; Castillo, J. R. Atom .Spectroscopy,17:201 (1996).

10. Gaspar, A.; Posta, J.; Toth, R. J.Anal .Atom Spectrom., 11: 1067 (1996).

11. Posta, J.; Gaspar, A.; Toth, R.; Ombodi, L. FreseniusJ. Anal .Chem., 355: 719 (1996).

12. Revanasiddappa, H. D.; Kiran Kumar, T. N. Talanta, 60: 1 (2003).

13. Hirata, S.; Umezaki, Y.; Ikeda, M. Anal. Chem., 58: 2602 (1986).

14. Greenberg, R. R.; Ziesler, R.; Kingston, H. M.; Sullivan, T. M. Fresenius' J. Anal. Chem., 332: 562 (1988).

15. Majors,R.E.LC-GC., 4: 972 (1989.

16. Hangen, D.F., Markell, C.G., Scmitt, G.A., Blevins, D.D. Anal. Chim. Acta., 236: 157 (1990).

17. A,Moghimi, M. Abdouss., Preconcentration of $\mathrm{Ni}(\mathrm{II})$ from sample water by modified poly (ethylene terephthalate)-grafted-acrylic acid/ acryl amide fiber), Afr. J. Pure Appl. Chem. 6(8):110-118 ((2012)).

18. H.Wang, H.S.Zhang, J.K. Cheng., Studies on 2-(2-thiazolylazo)-5-diethylaminophenol as a precolumnderivatizing reagent in the separation of platinum group metals by high performance liquid chromatography), Talanta 48: 1-8 (1999).

19. E. Porselvi and P. Krishnamoorthy, Orient J. Chem., 29(2): 719-723 (2013).

20. M.Zargaran, A. M.Shoushtari, M.Abdouss (Ion adsorption studies of micro and nano acrylic fibers modified by ethanolamine. Ionen Adsorption von mitEthanolamin modifiziertenMikro- und Nano-Acylfasern), J. Appl. Polym. Sci, 110: 3843-3849 (2008).

21. M.Tabarzadi, M. Abdouss, S. A.Hasani, A.M.Shoushtary, U.Mat.-wiss. (Ion adsorption studies of micro and nano acrylic fibers modified by ethanolamine. Ionen Adsorption von mit Ethanolaminmodifizierten Mikro- und Nano-Acylfasern)Werkstofftech. 41(4): 221 228 (2010).

22. D. H.Shin, Y. G.Ko, U. S. Choi, W. N. Kim., (Fluorescence Enhancement of Coumarin Thiourea Derivatives by $\mathrm{Hg}^{2+} \mathrm{Ag}^{+}$, and Silver Nanoparticles), Ind. Eng. Res. 43: 2060-2065 (2004).

23. P.Nayebi, A.Moghimi, (Perconcentration and Determination of copper(II) by 1-(2PyridyIAzo)2-Naphtol(PAN) modified Octadecyl Silica), Orient J. Chem., 22(3): 507-512 (2006).

24. O. R .Hashemi, K M.argar-Razi, F.Raoufi, A.Moghimi, H.Aghabozorg, M. R.Ganjali, (Ultratrace monitoring of copper in environmental and biological samples by inductively coupled plasma atomic emission spectrometry after separation and preconcentration by using octadecyl silica membrane disks modified by a new schiff's base) Microchem. J.69: 1-8 (2001).

25. Shamsipur, M.; Avanes, A.; Raoufi, M. K.; Sharghi, H.; Aghapour, G. Talanta, 54: 863 (2001).

26. Shamsipur, M.; Ghiasvand, A. R.; Sharghi, H.; Naeimi, H. Anal. Chim.Acta, 408: 271 (2000).

27. Ganjali, M. R.; Pourjavid, M.R.; Hajiagha Babaei, L.; Niasari, M. S. Quim. Nova, 27: 213 (2004).

28. Shamsipur, M.; Javanbakht, M.; Ghasemi, Z.; Ganjali, M. R., Lippolis, V.; Garau, A. Sep. Purif. Technol., 28: 141 (2002).

29. HajiaghaBabaei, L.; Ghasemi, Z.; Darciche, F.; Shamsipur, M.; Raoufi, F.; Ganjali, M. R. Anal. Sci., 17: 1305 (2001).

30. Shamsipur, M.; Shokrollahi, A.; Sharghi, H.; Eskandari, M. M. J.Hazard. Mater, 117: 129 (2005).

31. Chen, Z.; Yang, G.; Hu, Q.; Yin, J.; Su, Q. J. Chin. Chem. Soc., 51: 297 (2004).

32. Cesur, H.; Bati, B. Turk. J. Chem., 26: 29 (2002).

33. Farhadi, K.; Teimouri, G. Talanta, 65: 925 (2005).

34. Shamsipur, M.; Yousefi, M.; Ghasemi, Z.; HajiaghaBabaei, L.; Ganjali, M. R. Separ. Sci. Technol., 37: 3525 (2002).

35. Shamsipur, M.; Ghiasvand, A. R.; Yamini, Y. Anal. Chem., 71: 4892 (1999).

36. Wolf, S.F., Unger, D.L., Friedrich, J.M. Anal. Chim. Acta 528: 121 (2005).

37. W. S. Hummers, Jr., R. E. Offeman, J. Am. Chem. Soc. 80: 1339 (1958).

38. A.Moghimi,"Chinese Journal of Chemistry 25(10): 1536 (2007).

39. A. Moghimi; S.Ghammamy "Environmental chemistry an Indian journal”2(3): (2007). 